\title{
LVII. Determination of the dimensions of the earth, from the principal measurements of arcs of meridians
}

\section{Dr. Edward Schmidt}

To cite this article: Dr. Edward Schmidt (1830) LVII. Determination of the dimensions of the earth, from the principal measurements of arcs of meridians, Philosophical Magazine Series 2, 7:42, 409-412, DOI: $10.1080 / 14786443008675326$

To link to this article: http://dx.doi.org/10.1080/14786443008675326

曲 Published online: 13 Jul 2009.

Submit your article to this journal $₫$

Џll Article views: 2

Q View related articles $₫$ 


\section{Dr. Schmidt's Determination of the Dimensions of the Earth. 409}

rention; that the model shown corresponded in all its proportions with certain paddle-wheels manufactured by $\mathrm{Mr}$. W. J. Curtis about the middle of the year 1829, under the superintendence of Mr. E. Galloway; that in the conversation above alluded to, Williams at first denied either having seen the paddles made by Mr. Curtis, or any plan resembling the model shown (this he asserted with repeated solemn protestations, calling on God to witness their truth); and that he shortly afterwards admitted having seen the paddles made by Mr. Curtis, and having copied therefrom the essential parts of the machine-to wit, the radius collar, fixed crank, and the lengths of the radius rods:

That deponent remembers having seen Williams at the shop of $\mathrm{Mr}$. Curtis when the paddles were fixed and ready for exportation, and befcre Williams had commenced to make the model which he now asserts to be his invention.

Witness to the signing, WM. Sappo.

Sworn before me this 23rd day of January 1830, P. Laurie, Alderman.

\section{(Copy.)}

Alexander Park, Mechanical Draughtsman, of Nelson-Street, Borough of Southwark, maketh oath, and saith,

That on the eleventh of January 1830 he was in conversation with Mr. King Williams, machinist, who professes to be the inventor of a certain modification of paddle-wheels similar to the system recently patented by Mr. E. Galloway; that the said Williams then admitted to deponent, that he had copied certain parts of Mr. Galloway's machine from a set of paddles manufactured by $\mathrm{Mr}$. W. J. Curtis about the middle of the year 1827 ; that he had gained admittance to Mr. Curtis's premises by the connivance and assistance of a smith named Samuel Laing or Lang; and that he, Williams, had then and there measured the above-named paddle-wheels, for the purpose of making therefrom the model now shown as the invention of the said Williams. That Williams also admitted to deponent, that those parts of the paddile-wheel which deponent knows to constitute Mr. Galloway's patent had been accurately copied in the model; and that their dimensions were obtained by inspection and measurement of the paddles made by Mr. Corrtis.

Deponent further saith, that Williams solicited deponent to give plans of the subsequent improvements of $\mathrm{Mr}$. Galloway, for the purpose, asWilliams stated, of transmitting them, as his own invention, to the Editor of the Register of Arts and Sciences.

Alexander Park.

Witness to the signing, WM. SAPPO.

Sworn before me this 23 rd day of January 1830 ,

$$
\text { P. LAURIE, Alderman. }
$$

LVII. Determination of the Dimensions of the Earth, from the principal Measurements of Arcs of Meridians. By Dr. Edward Schmid?.

$\mathrm{N}$ the supposition of the earth being an elliptical spheroid, the figure of the generating ellipsis may be found from two arcs of meridians measured in different latitudes; but the

- From Prof. Schumacher's Astronomische Nachrichten.

N.S. Vol. 7. No. 42. June $1830 . \quad 3 \mathrm{G}$ applica- 
application of the formulæ derived from this assumption, to the different measurements which have been executed, has proved that every combination of any two of them gives a different result for those dimensions. It became, therefore, necessary to apply to the whole mass of the best measurements, a principle accordant with the nature of the subject, by which the most probable figure of the earth's surface, resulting from all of them, might be elicited. This has partly been done in an unfinished paper by Walbeck, entitled "Dissertatio de forma et magnitudine telluris, ex dimensis arcubus meridiani defuniendis." Walbeck has founded his researches on the principle that the sum of the squares of the differences between the measured and calculated arcs should be a minimum. But he neglected in these calculations the second power of the ellipticity, and likewise the partial arcs determined between the extreme points of a measurement; and his results were therefore susceptible of some improvements by a more accurate investigation.

Having been induced by Professor Gauss to take up this subject, I have taken into account the second power of the ellipticity, and have so far changed the above-mentioned principle, as to make the sum of the squares of the differences of the calculated and observed latitudes a minimum, instead of that of the squares of the differences of the measured and computed arcs of the meridian. The results of my calculation have been published by Prof. Gauss in his book entitled "Determination of the Difference of Latitude of the Observatories of Göttingen and Altona." But on a revision, a small error in calculation was discovered; and I became acquainted with a small correction which is to be applied to the English and East Indian measurements (see Phil. Trans., where Capt. Kater has proved that the lengths of the arcs in the East Indies are to be multiplied by $1-0.000018$, and those in England by $\left.1+0^{\circ} 000007\right)$. A new calculation therefore became necessary, which I here communicate.

Let $f$ denote the length of the mean degree (the three-hundred-and-sixtieth part of the terrestrial meridian), $\alpha$ its ellipticity; so that if $a$ represent the semiaxis major, and $b$ the semiaxis minor, we have $b=(1-\alpha) a$. Let it be assumed, that

$$
f=\frac{57009 \cdot 76}{1+\frac{u}{1000}} \text { toises, and } a=\frac{1+y}{302 \cdot 78} \text {; then the following }
$$

measurements give these final equations for determining $u$ and $y: \quad 72 \cdot 13=2100 \cdot 90 u+1763 \cdot 16 y$

$$
200 \cdot 77=1763 \cdot 16 u+9348 \cdot 66 y
$$


from the principal Measurements of Arcs of Meridians. 111

Hence we obtain

$$
\begin{array}{ll}
u=+0.01937669 & \text { Weight }=1768 \\
y=+0.01782113 &
\end{array}
$$

and the errors of the single latitudes are then as follows :

\section{Peruvian Measurement.}

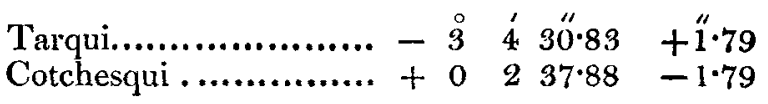

First East Indian Measurement.

Trwandeporum ......... + $1144.52 .59-0.59$

Paudree................ $131949.02+0.55$

Second East Indian Measurement.

$\begin{array}{lrrrr}\text { Punnac..................... } & 8 & 9 & 38.39 & -1.73 \\ \text { Putchapollian............ } & 10 & 59 & 48.93 & -1.21 \\ \text { Dodagooontah............. } & 12 & 59 & 59.91 & +3.50 \\ \text { Nantkabad............... } & 15 & 6 & 0.64 & -0.57\end{array}$

\begin{tabular}{|c|c|c|c|c|}
\hline era & 38 & & 56.11 & \\
\hline & 41 & & $45^{\circ}$ & \\
\hline Bal & 41 & 22 & & \\
\hline & 42 & 1 & & \\
\hline $\mathrm{Ca}$ & 43 & 12 & & \\
\hline & 46 & & 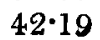 & \\
\hline & 48 & 80 & $48 \cdot 94$ & \\
\hline & & & $m$ & \\
\hline
\end{tabular}

French Measurement.

English Measurement.

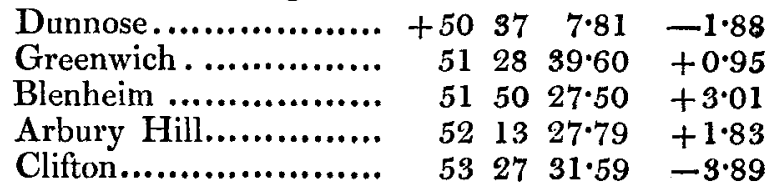

Hanoverian Measurement.

Göttingen............... $51 \quad 31 \quad 47 \cdot 85 \quad-2 \cdot 74$

Altona ................... $53 \quad 3245 \cdot 27+2 \cdot 74$

Sroedish Measurement.

Mallörn.................. $653131.06+1 \cdot 33$

Pahtawara................ $67 \quad 8 \quad 51 \cdot 41 \quad-1 \cdot 33$

The sum of the squares of these errors is $157^{11 \cdot 78}$; and hence results the mean error of a determination $=3^{\prime \prime} \cdot 140$. The mean errors are: of $u=0.074684$ of $y=0.035401$ 
Substituting the above values of $u$ and $y$ in the expressions for $\alpha$ and $f$, we find:

The three-hundred-and-sixtieth part of the terrestrial meridian $=0.57008 \cdot 655$ toises; the ellipticity $=\frac{1}{297 \cdot 479}$.

The mean error to which the value of $f$ is subject, is $=4.26$ toises; and the mean error to which the value of $\alpha$ is subject, is $=10.5$ unities of the denominator. We have next,

$$
a=3271852.32 \text { toises; } b=3260853 \cdot 70 \text { toises. }
$$

With regard to the formulæ applied in these calculations, I refer to the first volume of my "Mathematical and Physical Geography," the printing of which is nearly finished.

EDWARd SchMidT.

LVIII. On the Figure of the Earth. By James Ivory, Esq. M.A.F.R.S. \&c.*

THE 8th volume of the Mémoires de l'Academie des Sciences, published in 1829, contains a paper on the figure of the earth by $M$. Biot, who has had so great a share in the experimental researches relating to that subject. Accompanied with his son and assisted by him, M. Biot determined in 1824 the lengths of the pendulum at Milan, Padua, and Fiume, upon the parallel of $45^{\circ}$; and as the same parallel passes through the old stations of Bourdeaux, Figeac, and Clermont, we are thus made acquainted with the lengths of the pendulum at the six principal stations of the great arc perpendicular to the meridian, extending from Bourdeaux to Fiume, which has lately been measured geodetically with so much ability and exactness. We are indebted to the same observers for the pendulums at the two new stations of Lipari and Barcelona; and for a remeasurement of the pendulum at Formentera, the old length in the 4th volume of the Base Métrique being for some reasons deemed exceptionable. According to the new measurement, the pendulum at Formentera, in a vacuum and reduced to the level of the sea, is $993^{\mathrm{mm} \cdot 0697 \text {; }}$ the length as stated in the Base Métrique is equivalent to

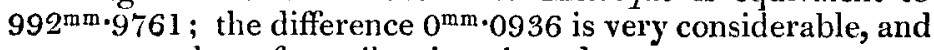
answers to about four vibrations in a day.

The most curious part of M. Biot's paper is an attempt to prove that the lengths of the pendulum in different latitudes are not accurately represented by the formula usually employed: for he finds that the coefficient of the term proportional to the square of the sine of the latitude, is not an invari-

- Communicatod by the Author.

able 